\title{
Therapeutic adherence in the Crisis Intervention Service of the Psychiatry Department
}

\author{
Raquel A. Sánchez-Núñez ${ }^{1 *}$ and Andrea F. Guerrero-Medrano² \\ ${ }^{1}$ Department of Psychiatry, University Hospital "Dr. Jose E. González"; ${ }^{2}$ School of Medicine. Autonomous University of Nuevo León, Monterrey, \\ Nuevo Leon, Mexico
}

\begin{abstract}
Objective: The objective of the study was to describe the therapeutic adherence in the crisis intervention service at the University Hospital "Dr. José E. González". Materials and methods: The present work is an observational, longitudinal, retrospective, and descriptive study. The records of the patients who were treated in the Crisis Intervention Service during the months of March 2018-May 2018 were reviewed. The demographic and diagnostic data were analyzed, as well as the continuity in the treatment over 6 months, whose cut point in research was in November 2018. Results: It was found that 63 patients were treated in the crisis intervention service. About 30\% (19 patients) continued their treatment until November 2018. Conclusion: The therapeutic adherence seen in the Crisis Intervention Service at this hospital is higher than or equal to that described in literature.
\end{abstract}

Key words: Therapeutic adherence. Crisis intervention. Brief solution-focused therapy.

\section{Introduction}

\section{General points of therapeutic adherence and intervention in crisis}

Therapeutic adherence is a patient's ability to correctly be involved in the choice, beginning and control of pharmacological and psychotherapeutic treatment, allowing him to maintain a rigorous compliance to said treatment, with the purpose of obtaining an adequate suppression of symptoms ${ }^{1}$.

The World Health Organization (WHO) defines it as "the extent to which a person's behavior - taking medication, following a diet, and/or executing lifestyle changes, corresponds with agreed recommendations from a health-care provider"2. The definition proposed by the WHO is ample, and it addresses adherence beyond the taking of medication. This article will go into the concept of therapeutic adherence as a group of recommendations by the treating physician in crisis intervention patients.

Lack of adherence to treatment is somewhat common, contributing to a worsening of the disease, and increasing the risk of death and health costs ${ }^{3}$.

Lack of adherence to psychiatric pharmacological treatment is very high, and it has negative consequences in the individuals, their families, and health systems. Moreover, psychiatric comorbidity is a risk factor for non-adherence to other treatments of metabolic conditions ${ }^{4}$. Most studies agree that the most significant relapse predictor in schizophrenia and bipolar disorders is lack of adherence ${ }^{5}$. The main modifiable protector factor in suicides of patients with bipolar disorder (follow-up of

\section{Correspondence:}

*Raquel A. Sánchez-Núñez

E-mail: alejandra.kafka@gmail.com
Available online: 09-12-2019

Date of reception: 18-01-2019

Date of acceptance: 28-08-2019 DOI: 10.24875/RMU. 19000050
Medicina Universitaria. 2019;21(4):152-156 www.medicinauniversitaria.org

1665-5796/@ 2019 Universidad Autónoma de Nuevo León. Published by Permanyer. This is an open access article under the CC BY-NC-ND license (http://creativecommons.org/licenses/by-nc-nd/4.0/). 


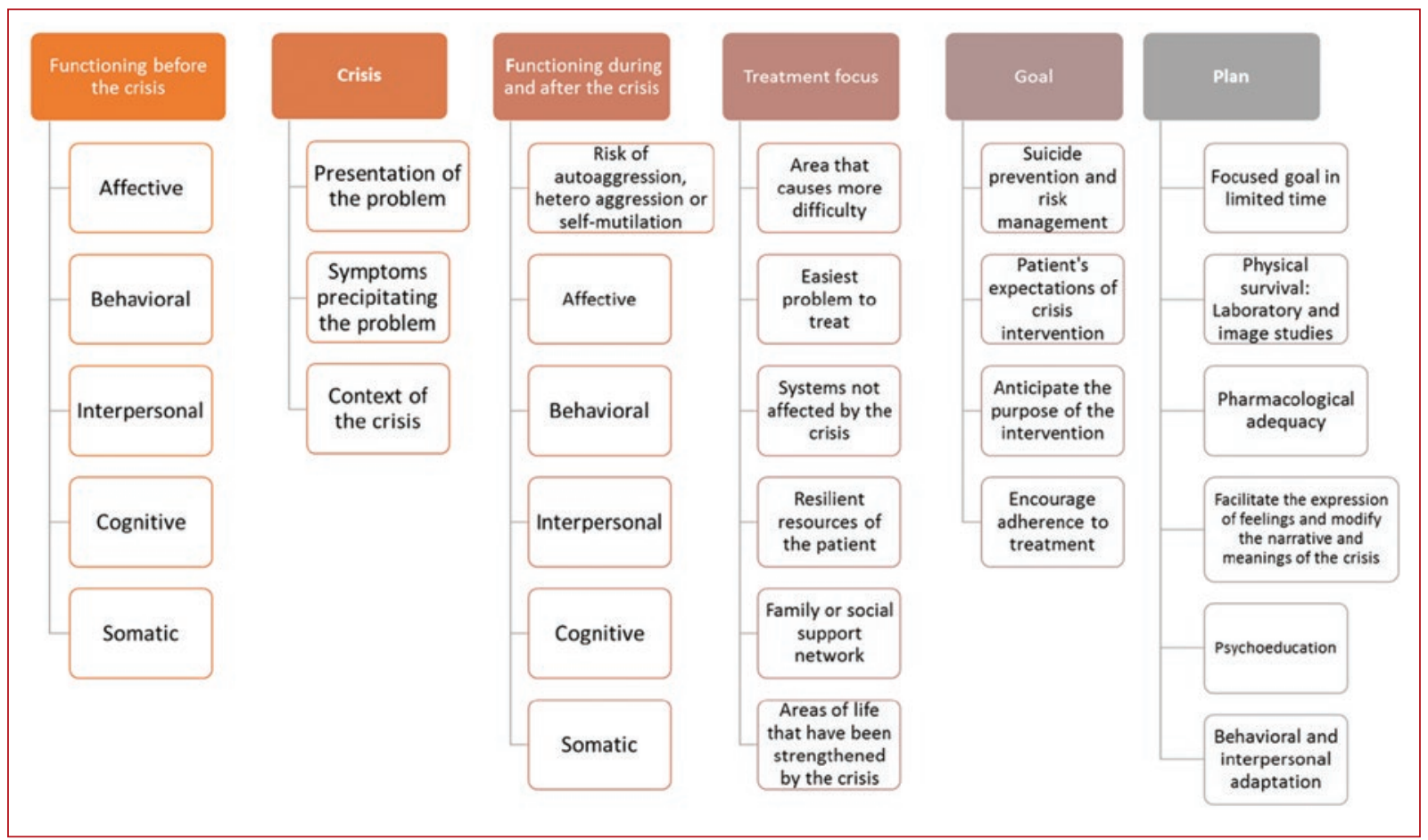

Figure 1. Model of crisis intervention based on solutions.

10 years) is adherence ${ }^{6}$. Lack of adherence to treatment in depression can make the physician think the treatment is not being effective, resulting in a dose increase or making unnecessary changes to antidepressants, which could elevate the risk of side effects ${ }^{7}$.

According to a survey on therapeutic adherence in Spain (2016), results showed that $28 \%$ of patients with depression adhered to the treatment; on the other hand, pathologies such as cancer or diseases like HIV have a far greater degree of adherence, with values $>70 \%^{8}$. Regarding attendance rate to programmed appointments at the Mental Health Service, our calculations suggested that failure to attend the first appointment was $21 \%$, the second appointment was $37.8 \%$, and the third appointment was $41.9 \%{ }^{9}$. Therefore, depression as well as other psychiatric conditions continue to be a challenge for health professionals to promote adherence to treatment.

\section{Crisis intervention}

Crisis intervention is an active process, centered on the immediate problem as the patient identifies and perceives it. It must be timely, flexible, and accessible. It is multidisciplinary work, which takes place in collaboration with the patient, family, treating physicians, social workers, and community. One of the theoretical models that underlie the application of crisis intervention is solution-focused brief therapy (SFBT) ${ }^{10,11}$.

\section{Fundamental guidelines of SFBT}

- If it is not broken, do not fix it

- Once you figure out what works, do more of the same

- If that does not work, do not try it again. Do something different.

\section{Materials and methods}

The objective of this article is to describe the prevalence of therapeutic adherence at the Crisis Intervention Service of the "Dr. Jose E. Gonzalez" University Hospital and propose the hypothesis that SFBT, which forms the foundation for this intervention, allows us to have an adherence similar to that reported in literature, and be able to elaborate a series of recommendations that can promote adherence to treatment in patients in crisis, as well as with other medical conditions.

This was an observational, longitudinal, retrospective, and descriptive study.

- Environment: Patients were recruited from the Crisis Intervention Service at the Outpatient Clinic of the Department of Psychiatry at the University Hospital of the UANL 
- Population: Over 18 years old and under 75

- With one of the following psychopathological conditions

- Suicidal thoughts

- Acute stress

- Acute affective disorder

- Risk of heteroaggression

- Either on psychopharmaceutics or not.

- General intervention model: Application of the model centered on solutions for patients in crisis (Fig. 1)

- Period: March-May 2018 and follow-up until November 2018.

One service provided by the "Dr. Jose E. Gonzalez" University Hospital is crisis intervention. This service is aimed at patients who are at risk of suicide, patients with severe depressive episodes, decompensation of a previous psychiatric disorder, or the $1^{\text {st }}$ time symptoms requiring an extensive approach and the patient or a family member decided to reject inpatient hospitalization, or they are waiting to be admitted.

A theoretical model justifying clinical application of the crisis intervention service is the SFBT model.

A schematic way of summarizing the SFBT model applied at the crisis intervention service can be represented using the mnemonic $A B C^{12}$.

- A for attention, actively listening, offering support, and activating support networks

- B for viewing (or looking), identifying the problem and the risk

- C for containing the problem, looking at previous attempts to solve the problem or crisis, offering alternatives, developing a plan, and promoting adherence to treatment.

The operational definition that we offer for adherence to treatment includes presenting at least one of the following aspects: (a) knowledge and acceptance of the treatment plan, having accepted the diagnosis or an initial evaluation, (b) compliance, that is, implementing the indications, accepting responsibility for the pharmacological and psychotherapeutic treatments, carrying out the tasks the treating physician recommends, attendance to scheduled appointments, (c) avoiding risky behavior, performing the necessary modifications to avoid worsening their emotional state, having a clear and detailed contingency plan in case of relapse, and finally, (d) incorporate healthy behavior into their lifestyle to improve their initial state ${ }^{13}$.

Ethical considerations: Patients who displayed suicidal risk were offered internment first, and only those who signed a negative to inpatient interment treatment were offered crisis intervention on a second instance.
Table 1. Demographical data

\begin{tabular}{|l|c|c|}
\hline $\begin{array}{l}\text { Patient } \\
\text { characteristics }\end{array}$ & Female & Male \\
\hline $\mathrm{n}(63)$ & 38 & 25 \\
\hline Average age & 25 & 23 \\
\hline $\begin{array}{l}\text { Most frequent } \\
\text { diagnosis }\end{array}$ & $\begin{array}{c}\text { Major depressive } \\
\text { disorder }\end{array}$ & $\begin{array}{c}\text { Major depressive } \\
\text { disorder }\end{array}$ \\
\hline
\end{tabular}

Demographical data, crisis intervention March 2018-May 2018.

Table 2. Adherence to treatment

\begin{tabular}{|l|c|c|}
\hline $\begin{array}{l}\text { Patient } \\
\text { characteristics }\end{array}$ & Female & Male \\
\hline $\mathrm{n}(19)$ & 13 & 6 \\
\hline Average age & 24 & 20 \\
\hline $\begin{array}{l}\text { Most frequent } \\
\text { diagnosis }\end{array}$ & $\begin{array}{c}\text { Major depressive } \\
\text { disorder }\end{array}$ & $\begin{array}{c}\text { Major depressive } \\
\text { disorder, in remission }\end{array}$ \\
\hline
\end{tabular}

Adherence to treatment after 6 months.

\section{Results}

Registers from patients in our database who were treated at the Crisis Intervention Service during the period of March 2018-May 2018 were obtained, from which we obtained a sample of 63 patients, of which 38 were female and 25 male; average age for women was 23 years old, and average age for men was 25 years old. In both groups, the most common diagnosis was major depressive disorder (Table 1).

Subsequently, a search for the patients out of the 63 who continued with treatment after 6 months of having started treatment was conducted, with a cutoff point of November 2018 (Table 2).

Findings showed that $30 \%$ (19 patients) complied with at least one criterion from the definition of therapeutic adherence after 6 months of having started treatment. The most common diagnosis was major depressive disorder, in remission. The treating physicians were interviewed on their subjective global impression of the improvement of said patients, and every single one of them said that the patients had shown positive changes in their mood and a reduction in suicidal thoughts.

\section{Discussion}

This paper has focused on describing the importance of fomenting adherence to treatment and to the results 
obtained in therapeutic adherence through SFBT applied to patients at the crisis intervention service.

The prevalence rate of failure in therapeutic adherence is more elevated among subjects with psychiatric disorders, and the consequences can be devastating.

Taking into consideration that the motives for a lack of adherence are many and varied, a single intervention is hardly effective. Logically, if individualized interventions are utilized for each patient, directed at different non-compliance barriers, the result will be more significant. SFBT allows for a particularized approach, at the present time, without reminiscing on causal or historical factors, stressing the therapeutic relation as a mutual collaboration, and not so much as a relationship which ought to be defeated or conquered, thus enabling work on an appropriate therapeutic adherence.

\section{Study limitations}

The data were obtained from the patients treated at crisis intervention, which constitutes a form of outpatient treatment (patients had rejected inpatient internment); therefore, they were exposed to a number of non-controlled variables that can affect the course of intervention, either positively or negatively.

\section{Perspectives for the future}

It is recommended that future studies continue with the observation of the evolution of the cases of patients attended at the crisis intervention service, increasing the studied sample, and conducting comparative studies of groups of patients attended with SFBT versus a different psychotherapeutic model (i.e., cognitive-behavioral therapy). In addition, it is recommended to document the changes observed in patients objectively through clinimetrics, changes observed in the areas of affective symptoms and suicidality.

\section{Recommendations to improve adherence to treatment}

- Strategies aimed at the physician ${ }^{14,15}$

- Recognizing the problem of non-compliance as predominant

- Multidisciplinary cooperation among the involved professionals

- Establishing a good therapeutic alliance

- Dedicating time to specifically assessing compliance
- Allowing involvement on behalf of the patient in decisions relative to his/her treatment

- Empathetic attitude, no judging or blaming

- Effective communication: Try to have the patient understand his/her treatment and make sure of it

- Availability for consultations related to adverse effects.

- Strategies aimed at treatment

- Keep treatment guidelines as simple as possible

- Adequate information on treatment and the disorder

- The selection of pharmaceutics with less potential for adverse effects

- Evaluating and approaching adverse effects

- Proposing a change to intramuscular treatment in cases of repeated non-compliance in patients with psychotic disorders.

\section{Conclusion}

According to the results, findings suggest that the crisis intervention service at the "Dr. Jose E. Gonzalez" University Hospital has a therapeutic adherence similar to or greater than that described in literature.

\section{Conflicts of interest}

The authors declare that they have no conflicts of interest.

\section{Ethical disclosures}

Protection of human and animal subjects. The authors declare that no experiments were performed on humans or animals for this study.

Confidentiality of data. The authors declare that they have followed the protocols of their work center on the publication of patient data.

Right to privacy and informed consent. The authors have obtained the written informed consent of the patients or subjects mentioned in the article. The corresponding author is in possession of this document.

\section{References}

1. Olatz IB, Ramón MR. Lo que Debes Saber Sobre la Adherencia al Tratamiento. Sociedad: Sociedad Española de Farmacia Hospitalaria; 2017.

2. World Health Organization. Adherence to Long-term Therapies: evidence for action. Genève: World Health Organization; 2003.

3. Heaton PC, Tundia NL, Luder HR. U.S. Emergency departments visits resulting from poor medication adherence: 2005-07. J Am Pharm Assoc. (2003) 2013;53:513-9.

4. Chapman SC, Horne R. Medication nonadherence and psychiatry. Curr Opin Psychiatry. 2013;26:446-52.

5. Fleiscbhacker WW, Oehl MA, Hummer M. Factors influencing compliance in schizophrenia patients. J Clin Psychiatry. 2003;64:10-3. 
6. Ugarte A, Martínez-Cengotitabengoa M, Alberich S, Sáenz M, Karim M, González-Pinto A. Adherence and depression in bipolar patients with suicidal risk. In $5^{\text {th }}$ Biennial conference of the international society for bipolar disorders. Istanbul, Turkey. Bipolar Disord. 2012:14 Suppl 1:S132.

7. Cohen NL, Ross EC, Bagby RM, Farvolden P, Kennedy SH. The 5-facto model of personality and antidepressant medication compliance. Can $J$ Psychiatry. 2004:49:106-13.

8. Fundación Farmaindustria Sociología y Comunicación. España: Encuesta Sobre Adherencia Terapéutica en España; 2016.

9. Robles ML. La adherencia terapéutica en el tratamiento y la rehabilitación: implicaciones para el profesional de la conducta y la salud. Rev Griot. 2016;7:73-84.
10. Roberts AR. Crisis Intervention Handbook. New York: Oxford University Press; 2005:64-89.

11. Martínez FG, Ceberio M. Manual de Terapia Sistémica Breve. Chile: Mediterráneo Ltd.: 2016.

12. Johnny SK. Examining the effectiveness of solution focused brief therapy: a metanalysis using random effects modeling. Res Soc Work Pract. 2008;18:107-16.

13. Flórez L. Psicologiá Social de la Salud. Bogotá: Manual Moderno; 2007.

14. Nieuwlaat R, Wilczynski N, Navarro T, Hobson N, Jeffery R, Keepanasseril $\mathrm{A}$, et al. Interventions for enhancing medication adherence. Cochrane Database Syst Rev. 2014; 11:CD000011.

15. Gurina JG. Efectividad de las Estrategias Para Mejorar la Adherencia Terapéutica en Pacientes Crónicos. España: Revisión Meta-análisis; 2016. 